This operation having proved unsuccessful I decided to alter the procedure, and in the following June the left eye was operated upon. As in the other eye, an anterior sclerotomy was performed, but the incision was extended so as to cut

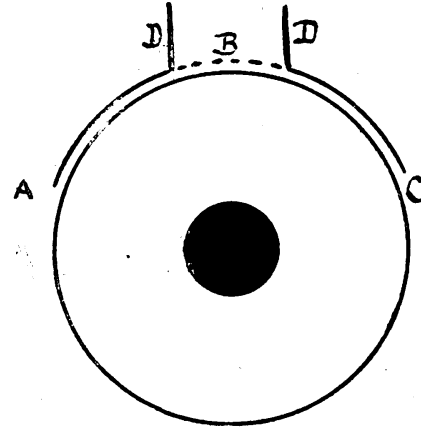

Fig. 1.-Diagram showing extent of incision. A. B, C, Incision through sclera; $B$, point at which bridge of conjunctivel tissue entirely through the upper part of the intercalary region. The knife as it emerged through the sclera above the cornea was not allowed to cut through the conjunctiva, but this membrane was undermined for a few millimetres, producing a bridge of tissue which held the flap-like portion of the cornea in position.

The idea of this operation was to obtain a scar at the filtration angle, which would be sufficiently loose and porous to allow the intraocular fluid to escape through it under the conjunctiva, and so produce a permanent drain. The result more than fưlfllled my expectations ; a s mal cystoid cicatrix developed at the upper point of the incision and a minute fistnlous opening in the sclera at this point could be detected. The tension soon became normal, and the symptoms gradually abated.

In September, 1908, a similar operation was performed on the right eye, with an equally satisfactory result, and in December

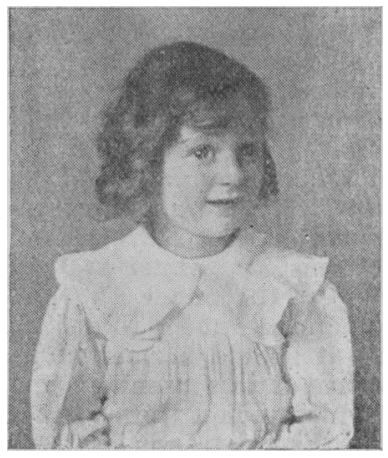

Fig. 2.-Photograph of Freda C. at the present time. of that year the intraocular tengion of both eyes mal, the photophobia had completely disappeared, and the child could see very much better. She could readily perceive a pin lying on the floor some yards away, and had accurate colour perception. The fields of vision were not markedly contracted.

In January, 1909, tension was In January, 1909, tension was
still normal in both eyes ; there was no injection, and the small cystoid cicatrices caused no irritation or discomfort. The corneal nebulae had nearly disappeared, and the eyes were much less prominent. The fields of vision, as far as they could be investigated, showed no contraction. The optic were not cupped, and the vision was rapidly improving.

Since that time I have seen her periodically, and the improvement has been maintained. In November, 1909, the tension was normal on both sides, and the sight was very good. A small astigmatic error was discovered, corrected by $8-2 \mathrm{D}$. cylinder $15^{\circ}$ from the horizontal in each eye, and with these correcting glasses she could read easily Jaeger 5 at about 6 in. Objects about the room could be distinguished with clearness and precision.

The child presents now an almost normal appearance, the eyes merely resembling the slightly prominent globes of a myope. She is bright, happy, and intelligent, and no longer complains of any eye symptoms.

This result, considering the usually hopeless nature of the disease, warrants me, I think, in recording the case, and will, I trust, lead to the relief of many future cases by a similar operative procedure.

\section{NOTES ON A CASE OF CYCLOPHORIA.} BY

\section{A. ALISON BRADBURNE, F.R.C.S.EDIN.,} SOUTHPORT AND MANCHESTER.

Cyclophoria is the condition which is associated with an abnormal rotation of the eyes. It is therefore a subject which belongs essentially to the sphere of the ophthalmic surgeon, but my reason for drawing attention to it is that it can, when untreated, lead to a state of matters which becomes really serious for the patients and most unsatisfactory for those whose duty it is to treat them. The reason for this is twofold-the absence of signs or symptoms to direct the attention of the examiner or the patient to the true seat of the cause; and also the considerable degree of ignorance which seems to exist, even in the majority of textbooks, concerning even the very existence of such a condition. Further it is important to recognize that it can be brought about by error in the ordering of glasses, and its existence should therefore be borne in mind by those who are in the habit of prescribing glasses.

The following is the statement which a patient I saw last August-a cashier aged 48-wrote concerning himself (names omitted) :

In 1894 I consulted Dr. - about my eyes; for a time the glasses were satisfactory, but by the year 1900 I had been to see three eye specialists, and the glasses they prescribed gave little ease or satisfaction for long. Between 1900 and 1907 I consulted an optician two or three times whose modification gave some satisfaction. Trouble then ensued again, and the optician could give me no relief. In the spring of 1907 I first experienced sensation of collapse or unconsciousness after walking two or three hundred yards in the noisy streets of Manchester, after working at figures and correspondence, and after railway travelling. In 1907 I again consulted an ophthalmic surgeon, who said: "That there was no trace of disease; that the unpleasant symptoms resulted from overwork; that the glasses last made by the optician were right ; that if I persistedly overworked my eyes some form of epilepsy would certainly result." I then consulted my local doctor, who advised me to give up me that my heart was not responsible for the trouble; that my general condition was very good; that he was certain that my trouble came from my eyes, and urged an effort to find correct glasses. In 1908 I consulted another optician, who tried various glasses. In 1908 I consulted another optician, who tried various In the same year I consulted a nerve specialist, who said I was simply run down through overwork; that the eye condition was secondary, and that I must take a cruise in the Mediterranean, and if I did he would guarantee a cure. I did this at great expense, but only to find a return of all my symptoms within a few weeks of my return. I then consulted a hydropathic physician, who said that I was suffering from optic neuritis physician, who said that I was suffering from optic neuritis treatment for one month with little benefit. Finally, I consulted another doctor, who sent me to see you.

I experienced at times a dull, aching, intermittent pain about the eyeballs and eyebrows, always finishing in the right eye, leaving a sensation of numbness, always aggravated by near work, followed sometimes by a feeling as if I were going to collapse and become unconscious. It is unaccompanied by noises in the head, though noises aggravate it. Am sometimes left slightly deaf for a time. I never see double, and external objects do not revolve.

Questioned further, he said that after any lengthened period of application to near work he had noticed on getting up from his desk that the ground seemed to slope up towards him. His general medical history was good. His father was alive and his mother lived till 70 . He had no brothers or sisters. He was a widower with two healthy children. He was almost a total abstainer as regard tobacco and alcohol. Except for his nerve troubles he enjoyed very good health.

Here, then, was a person who was evidently auffering from a condition which had been more or less present for fifteen years. If we carefully consider the history we see that the intensity of the symptoms has increased much more rapidly since he reached the presbyopic age; this points to a definite relationship to his near work. Again, we notice that his symptoms were always aggravated by near work and that relief followed cessation from such work.

These points taken together with the slowness of onset and the temporary relief only obtained by the various glasses tried, justify the conclusion that the cause must be of a trifling but persistent nature. Persistent because of its effects, and trifling because of its escaped detection.

I found that he was wearing one pair of glasses for near and far work. In front of the right eye he had a simple convex glass, but in the left was a strong convex cylinder placed at an angle of 25 degrees from the vertical. I assumed at once that his trouble arose from the position of this cylinder. If one of these cylinders be held about a foot or two in front of the eyes, and looked through it at, say, the bars of a window, and it then be rotated slowly it will be noticed that the bars seen through the glass become rotated out of alignment with those seen outside the glass. As this is what occurs when the cylinder is rotated, it is easy to see what happens when the eyes rotate and the cylinder is fixed. It is well known that the eyes turn in when a near object is looked at, such as a book, as in the act of reading, but at the same time they rotate on a fore and aft axis in such a manner that their vertical meridians become tilted out at their upper ends. This movement is exactly like that which occurs when the steering wheel of a ship is turned. 
In the case under consideration I found that he was wearing a cylinder the axis of which was placed leaning 25 degrees from the vertical; this position made all vertical meridians correct when his eyes were directed straight ahead, when in fact no torsion of his visual axes was present. It is plain, then, from what has been said about the rotation which occurs when the ejes are turned in, that this position of the cylinder could not be the correct one when he was looking down and in, for rotation will have taken place behind the lens. This it was quite simple to prove. A plain sheet of paper was placed at the usual reading distance from his eyes; with his distant glasses on a double prism was put in front of his right eye. On the card was a single straight line, to which he directed his attention. He then saw three lines; the upper and lower belonged to his right eye, the centre to his left. If, then any rotation of his eye were present, it was plain that this central line would not be parallel with the other two. As I expected, he stated that this middle line sloped away down to the right. By simply moving the position of the cylinder 10 degrees nearer the horizontal, this line became at once parallel. However, on once more testing, with the cylinder in this new position, with the eyes directed straight ahead, he stated that his vertical meridians were out of truth. Their restoration was effected by putting the lens back to its original position.

It was evident, then, that he needed two pairs of glasses, one for distant use with the cylinder at its old situation and another with it at ten degrees nearer the horizontal for reading and close work. After using these for three weeks he wrote to say that there was already some improvement.

Here, then, was a cause which answered to the hypothesis that the error was trifling, yet constantly and easily overlooked. We have only, then, to explain briefly what caused it to give rise to such symptoms.

It was evident that his glasses for distant use were perfectly correct, but when he came to read with them the rotation of the eyes which then took place would lead to a want of parallelism of the lines of his book. These lines would, in fact, tend to cross when the images were fused, but as the brain will not tolerate double images it would make every effort to correct this want of alignment. This is orercome by a special effort on the part of the oblique muscles of the eyes, whose function it is to rotate the ejes.

Now, this torsional action of the obliques is directed and graduated by the will, and though this effort of the will may be easy and rapid it is none the less an independent action.

This characteristic feature explains how it was that this cause could persist so long before it produced any symptoms. At first the extre exertion would entail little strain on the nervous output of energy, but as time wenti on, and he approached the age when reading naturally became more difficult, its effects on the general nerrons system would become more pronounced.

The phenomenon of the sloping of the ground, which was noticed after near work, is explained by the cramped position into which the oblique mascles had brought the eyes, causing them to become fixed in a position which made them incorrect for the gaze when directed straight ahead. This would also explain the trouble he experienced as he walked home through the "noisy streets of Manchester," as the lines of the buildings, etc., would all be out and his nerves in a highly sensitive condition to any external irritants.

This ease is an example of the endless troubles to which such a condition ean put both the patient and his medical advisers when it remains untreated and unrecognized.

Patient writes Docember 28th, 1909 : "There can be no doubt that an improvement in my condition has taken place during the last fow months ... but though feeling my physical limitations I can safely say my condition is better than it was."

THE second International Congress on Cancer Research will be held this year in Paris from October lst to 5th The President is His Excellency Professor von Czerny; the General Secretary, Dr. G. Meyer. The office to which all communications should be addressed is at 13, Bendler. strasse, Berlin, W.

\section{ON A TRIAL OF NASTIN.}

By J. ASHBURTON THOMPSON, M.D., D.P.H., PERMANENT heAD, DEPARTMENT OF PUBLIC HEALTH, NEW SOUTH WALES.

THe treatment of leprosy is still the opprobrium of therapeutics, and promise of improvement in it has so much importance that the following account of a trial of Professor Deycke's nastin treatment will have interest for many in different parts of the world who have reported on, or who are still conducting, similar trials. It is con. fined to a summary statement for want of space. Here, for instance, charts of daily temperature extending over a whole year cannot be displayed, but it has been abstracted from $m y$ annual official records ${ }^{1}$ for the years 1908 and 1909, in which such charts have been published, together with many other details not reproduced here. I would ask the reader to understand, therefore, that the statements made below do not represent general impressions, but result from clinical notes made from week to week. It is the more important to mention this in the case of leprosy, because the character of the disease is tenacity with long duration; oren its untreated course is commonly remittent or fluctuating, is frequently interrapted by long terms of quiescence, and, not very rarely, is brought to a close, apparent or real, in a stage which may be accepted as recovery for all practical purposes. These features leprosy has naturally, but when patients are cared for other points have to be borne in mind. It must be generally known, I suppose, that lepers almost invariably improve considerably after having been removed from conditions of poverty, or even of irregular living, to those of a well.ordered hospital, and that often the improvement is not confined to their general state-as shown, for example, by increase of weight-but extends to the visible and tangible stigmata of the disease. Over and above that, I have noticed that the stigmata vary considerably from time to time, independently of all treatment; and, again, that lepers are usually very impressionable, and often benefit remarkably, for a time at least, when interest and hope are excited in them by any new treatment; and, therefore, it is hardly enough for writers to assert that whereas before treatment a patient exhibited such and such signs, these afterwards became favourably modified or disappeared. In order that the mere reader may be placed as far as possible in a position to judge whether the reporter's opinion has been well founded, all the conditions under which the patient lay must be mentioned at the same time.

After having studied Professor Deycke's earlier papers, ${ }^{2}$ it seemed to me that his ingenious and interesting observations rested on foundations which were very largely speculative; but, farther, that application of the result of his experiments to treatment was a widely different matter. In his opinion, formed after long experience, his clinical results testified that a step towards the scientific treatment of this ancient disease had been taken by him for the first time in its history. On that ground I took nastin into use at the beginning of 1908 . My supplies, received from Biebrich, included nastin $\mathrm{B} 1$, nastin $\mathrm{B} 2$, and ketin; they were contained in original packages, and were in good order. The injections were actually administered by the medical superintendent of the hospital to which the lazarets are attached, Dr. R. J. Millard, M.B., D.P.H., who was formerly microbiologist in my department; the syringes were invariably dried by immersion in ether, which was allowed to evaporate before the nastin was drawn into them, and the remains of any partly emptied flask were thrown away. In no case did suppuration occur, but effects were produced at the site of injectionslight pain, which usually passed off in half an hour, with subsequent formation of hard and tender lumps. The latter resembled those caused by Haffkine's plague prophylactic, bat were so much more persistent, that at the end of the course each patient had large areas of irregular subcutaneous induration on the outer sides of the arms used; and, in the cases of two patients at least, these areas still persist quite plainly, although a year has elapsed since the last injection was made. Nothing further happened in the third, fourth, and fifth of the cases described below, but in the second there was additionally quite severe pain on three occasions, which persisted for 